\title{
Measurements and Factors of Biased Technological Progress in China's Marine Economy
}

\author{
Wang-Lin Kang', Yu-Kun Zou', Lei Wang, ${ }^{2,3 *}$, Xin-Min Liu ${ }^{4}$ \\ ${ }^{1}$ College of Economics and Management, Shandong University of Science and Technology, Qingdao, P.R. China \\ ${ }^{2}$ School of Economics, Ocean University of China, Qingdao, P.R. China \\ ${ }^{3}$ Marine Development Studies Institute of OUC, Key Research Institute of Humanities and Social Sciences at \\ Universities, Ministry of Education, Qingdao, P.R. China \\ ${ }^{4}$ School of Management, Qingdao Agricultural University, Qingdao, P.R. China
}

Received: 14 October 2019

Accepted: 4 March 2020

\begin{abstract}
A new technology may be biased towards saving energy, or reducing pollution emission or increasing economic output. It is necessary for the high-quality development of marine economy to promote environment-based technological progress. The purpose of this paper is to estimate the biased technological progress and its influencing factors of China's marine economy from 2002 to 2016. We used a DEA-Malmquist model to measure the biased technological progress. Then we further analyzed influencing factors of biased technological progress. Our research found that the TFP of the marine economy was basically growing, and this growth was mainly due to a positive impact of technological progress. In general, the technological progress of marine economy is gradually biased towards energy conservation and emissions reduction. Furthermore, technological progress in the Yangtze River Delta are more conducive to energy conservation. The marine economic production in the Pan-Pearl River Delta is more inclined to promote production growth, while tit is most concerned about environmental protection in the Bohai Rim region. In addition, factors such as environmental regulation, economic level, FDI and industrial scale have different impacts on biased technological progress of marine economy. The results show that the directive regulations have a greater impact on the input-biased technological progress, while the incentive regulations have a greater impact on the output-biased technological progress. Therefore, this study has important guiding significance for energy conservation and emission reduction of marine economy in China. And the green development path of China's marine economy can provide a reference for the development of European blue economy.
\end{abstract}

Keywords: biased technological progress, marine economy, total factor productivity, environmental regulation, space panel model

*e-mail: wlei.123@163.com 


\section{Introduction}

Since the 1990s, marine competition between countries has been a hot topic, and marine economy has occupied an increasingly important position in the economy of coastal states. With the development of economy, the concept of blue economy has received more attention [1]. The European Union has released the EU Blue Economy Report (2018), which points out that the EU's blue economy has strong momentum and become an important engine for the EU's economic growth [2]. Similarly, the Chinese government has proposed a strategy for building the " $21^{\text {st }}$ Century Maritime Silk Road". It is a major strategy for China to adapt to the new situation of economic globalization and expand the convergence of interests with countries and regions. The Global Ocean Technology Innovation Index Report (2018) released by China shows that the top ten countries in the global ocean technology innovation index are: the United States, Germany, Japan, France, China, South Korea, Australia, the Netherlands, Norway and the United Kingdom. China's ranking has risen steadily and has already ranked among the top five. Hence the development of China's marine economy is of great importance to the global marine economy.

In 2018, China's total marine production reached 1.26 trillion dollars, accounting for $9.3 \%$ of GDP. Among them, the added value of marine first, second and third industries accounted for $4.4 \%, 37.0 \%$, and $58.6 \%$ of the total value of marine production. The data shows that China's marine economy will achieve high-quality development in many aspects. Particularly, technological innovation can promote the high-quality development of marine economy. But previous studies of marine economic growth have been based on neutral technological progress in neoclassical growth theory [3-4]. In fact, in actual production processes, technological progress tends to use different factors, and it is biased. Due to the different preferences for factors, different biased technological progress are often presented. In addition, there are some problems with the current development of the marine economy, such as the reduction of resources and the deterioration of environment [5]. Green-biased technological progress about energy conservation and emission reduction can stimulate the high-quality development of ocean economy. Hence, it is necessary to analyze the bias of ocean economic technology and its influencing factors under the restrictions of energy and environment.

In the past decade, quite a few scholars have analyzed the marine economic growth in different countries, including Korean, England, China, etc [6-9]. Their research shows that the ocean economy plays a huge role in the national economy. At the same time, the rapid development of marine economy cannot be separated from technological progress [10]. Research by Morrissey et al. shows that the marine technology industry occupies an important position in the development of the Irish marine economy [11]. However, their study did not consider the undesired output of pollution emissions, ignoring the environmental pollution caused by marine economic production. Study by Sarker et al. shows that pollution and human interference are the main challenges for the further development of Bangladesh's blue economy [12]. Neglecting the constraints of environmental and resource lead to overestimation of real productivity growth [13]. The experience of the United States' marine economic development shows that effective management decisions will promote the development of ocean economy and environment [14]. What's more, by introducing Malmquist-Luenberger productivity indexes into a three-stage DEA model, it was found that technology inefficiency was the major cause of the inefficiency in China's marine economy [15]. However, they did not regard environment-biased technological progress as a research focus. In general, biased technological progress, which was in the context of the reduction of marine resources and the deterioration of marine environment, was rare in extant literature. Zapelloni et al. proposed that technological improvements could promote a circular economy and improve the marine environment [16].

In fact, Hicks' wage theory has the concept of "inducing innovation", while the idea of biased technological progress is alike. And technological innovation has a positive effect on maximizing the use of production inputs [17]. Hence, several studies paid close attention to the path of technical advancement affecting the income gap between labour and capital [18-19]. However, Acemoglu [20-22] established a theoretical framework for biased technological change and proposed the concept of environmentbiased technological progress. The environment-biased technological change could save a large number of scarce resources and reduce pollution emissions. Some scholars have focused their attention on the biased technological progress between inputs [23-26]. With the increasing awareness of energy saving and emission reduction, many authors take energy and pollution emissions into account when analyzing the biased technological progress to reflect the restrictions of energy and environment [27-29]. For example, Song et al. proposed a method to measure the abilities of energy conservation and emission reduction [30]. Further, $\mathrm{Li}$ et al. measured input-biased and output-based technological progress based on water resources for 30 areas in China [31]. They found that continuous growth of total factor productivity (TFP) was mainly driven by green-biased technological progress. In short, previous researches lack an analysis of biased technological progress of marine economy.

Based on a DEA-Malmquist model, we measure the biased technological progress of China's 11 coastal areas from 2002 to 2016 to support the high-quality development of marine economy. And we combine the dynamic changes of inputs and outputs to judge the bias of technological progress is energy conservation, 
or economic production, or environmental protection. China will continue to promote the high-quality development of marine economy and actively improve the construction of marine economic system. Further, we analyze the relevant influencing factors of biased technological progress. The determination of these influencing factors has policy implications for energy saving and emission reduction. Different technological advances tend to directly affect the allocation of resources in marine economic activities and have different impacts on the marine environment. Thus, defining the influencing factors can contribute to the high-quality development of China's marine economy.

This paper makes up for the shortcomings of the previous literature from two aspects. Firstly, a new technology may be biased towards resource conservation, or reducing pollution emissions or increasing economic output. In the past, the discussion of technological progress in the literature was mostly based on input orientation, focusing on technology advancement biased towards a certain production factor to optimize resource allocation, while ignoring output-biased technological progress. Therefore, we divide the biased technological progress into energy conservation-biased, emission reduction-biased, and production-biased technological progress, which makes up for the shortcomings of previous literature that ignore the research of outputbiased technological progress. This classification has important significance for green technological innovation and provides a healthy development path for China's marine economy. Secondly, this study fully considers the influence of environmental regulation on the biased technological progress of marine economy. At the same time, the different influences of directive or incentive environmental regulations on the inputbiased and output-biased technological progress are studied. Different from the influence of environmental regulations on the biased technological progress in the industrial field [32], this study shows that directive regulations can influence input-based technological progress, while incentive regulations are not conducive to promoting output-biased technological progress.

\section{Methods and Data}

\section{DEA-Malmquist Model}

There are usually two methods for measuring biased technological progress in previous studies, one is a parametric method and the other is a nonparametric method [33]. One of the common nonparametric methods is the DEA model. It has the advantage of allowing multiple inputs and outputs to be considered simultaneously, without the need to presuppose the form of the production function. Due to the diversity of production forms and the many influencing factors of technological progress, we chose DEA model as the main research method of this paper.
We assume that the number of decision-making unit (DMU) is $\mathrm{K}$. Every DMU produces $\mathrm{N}$ inputs, $x=\left(x_{1}, x_{2}, \ldots, x_{N}\right) \in R_{N}^{+} ;$M outputs, $y=\left(y_{1}, y_{2}, \ldots, y_{M}\right)$ $\in R_{M}{ }^{+}$. In fact, in the face of environmental regulations and limited resources, companies often want to increase expected output while reducing environmental emissions. In order to determine whether technological advancement is biased towards promoting production or reducing pollution, this study included positive environmental output in $y$. Then on the basis of the traditional direction distance function, the output distance function at period $t$ is built as follows:

$$
D_{i}^{t}\left(x^{t}, y^{t}\right)=\inf \left\{\theta:\left(x^{t}, y^{t} / \theta\right) \in P^{t}(x)\right\}=\left(\sup \left\{\theta:\left(x^{t}, \theta y^{t}\right) \in P^{t}(x)\right\}\right)^{-1}
$$

...where, $P^{t}(x)$ is the production possibility set. Further, under the condition that the scale return is unchanged, $D_{i}^{t}\left(x^{t}, y^{t}\right)$ can be acquired by solving the equation as follows:

$$
\begin{aligned}
& {\left[D_{i}^{t}\left(x_{k^{\prime}}^{t}, y_{k^{\prime}}^{t}\right)\right]^{-1}=\max \theta^{k^{\prime}}} \\
& \text { s.t. } \sum_{k=1}^{K} \lambda_{k}^{t} x_{k n}^{t} \leq x_{k^{\prime} n}^{t}, n=1,2, \ldots, N \\
& \sum_{k=1}^{K} \lambda_{k}^{t} y_{k m}^{t} \geq \theta^{k^{\prime}} y_{k^{\prime} m}^{t}, m=1,2, \ldots, M \\
& \lambda_{k}^{t} \geq 0, k=1,2, \ldots, K
\end{aligned}
$$

...where, $\lambda_{k}^{t}$ is non-negative weight variables. Similarly, we can obtain $D_{i}^{t+1}\left(x^{t+1}, y^{t+1}\right), D_{i}^{t}\left(x^{t+1}, y^{t+1}\right)$ and $D_{i}^{t+1}\left(x^{t}, y^{t}\right)$ by solving similar linear equations. Therefore, we estimate the growth rate of TFP by the Malmquist index method according to researches of Färe et al. [34] and Weber et al. [27], as shown in the following equation:

$$
M I=\sqrt{\frac{D_{i}^{t+1}\left(x^{t+1}, y^{t+1}\right)}{D_{i}^{t+1}\left(x^{t}, y^{t}\right)} \times \frac{D_{i}^{t}\left(x^{t+1}, y^{t+1}\right)}{D_{i}^{t}\left(x^{t}, y^{t}\right)}}
$$

Further, the MI index can be broken down into the technical efficiency change (EC) and the technological change (TC) as follows:

$$
\begin{aligned}
M I & =E C \times T C \\
E C & =\frac{D_{i}^{t+1}\left(x^{t+1}, y^{t+1}\right)}{D_{i}^{t}\left(x^{t}, y^{t}\right)} \\
T C & =\sqrt{\frac{D_{i}^{t}\left(x^{t}, y^{t}\right)}{D_{i}^{t+1}\left(x^{t}, y^{t}\right)} \times \frac{D_{i}^{t}\left(x^{t+1}, y^{t+1}\right)}{D_{i}^{t+1}\left(x^{t+1}, y^{t+1}\right)}}
\end{aligned}
$$

We further decompose the TC index to obtain the output-biased technological change (OBTC), the inputbiased technological change (IBTC), and the magnitude of technological change (MATC) as follows: 
Table 1. Biased technical progress and changes in factor mix.

\begin{tabular}{|c|c|c|}
\hline Factor mix & \multicolumn{2}{|c|}{ Biased technological progress } \\
\hline \multirow{2}{*}{$\left(\mathrm{x}_{1} / \mathrm{x}_{2}\right)^{\mathrm{t}+1}>\left(\mathrm{x}_{1} / \mathrm{x}_{2}\right)^{\mathrm{t}}$} & IBTC $>1$ & Use more energy, reduce labor \\
\hline & IBTC $<1$ & Use more labor, reduce energy \\
\hline \multirow{2}{*}{$\left(\mathrm{x}_{1} / \mathrm{x}_{2}\right)^{\mathrm{t}+1}<\left(\mathrm{x}_{1} / \mathrm{x}_{2}\right)^{\mathrm{t}}$} & IBTC $>1$ & Use more labor, reduce energy \\
\hline & IBTC $<1$ & Use more energy, reduce labor \\
\hline \multirow{2}{*}{$\left(\mathrm{x}_{1} / \mathrm{x}_{3}\right)^{\mathrm{t}+1}>\left(\mathrm{x}_{1} / \mathrm{x}_{3}\right)^{\mathrm{t}}$} & IBTC $>1$ & Use more energy, reduce capital \\
\hline & IBTC $<1$ & Use more capital, reduce energy \\
\hline \multirow{2}{*}{$\left(\mathrm{x}_{1} / \mathrm{x}_{3}\right)^{\mathrm{t}+1}<\left(\mathrm{x}_{1} / \mathrm{x}_{3}\right)^{\mathrm{t}}$} & IBTC $>1$ & Use more capital, reduce energy \\
\hline & IBTC $<1$ & Use more energy, reduce capital \\
\hline \multirow{2}{*}{$\left(\mathrm{y}_{1} / \mathrm{y}_{2}\right)^{t+1}>\left(\mathrm{y}_{1} / \mathrm{y}_{2}\right)^{\mathrm{t}}$} & 0BTC $>1$ & Promote economic production \\
\hline & 0BTC $<1$ & Reduce pollution emissions \\
\hline \multirow{2}{*}{$\left(\mathrm{y}_{1} / \mathrm{y}_{2}\right)^{\mathrm{t}+1}<\left(\mathrm{y}_{1} / \mathrm{y}_{2}\right)^{\mathrm{t}}$} & $0 \mathrm{BTC}>1$ & Reduce pollution emissions \\
\hline & $0 \mathrm{BTC}<1$ & Promote economic production \\
\hline
\end{tabular}

$$
\begin{aligned}
& T C=O B T C \times I B T C \times M A T C \\
& \text { OBTC }=\sqrt{\frac{D_{i}^{t}\left(x^{t+1}, y^{t+1}\right)}{D_{i}^{t+1}\left(x^{t+1}, y^{t+1}\right)} \times \frac{D_{i}^{t+1}\left(x^{t+1}, y^{t}\right)}{D_{i}^{t}\left(x^{t+1}, y^{t}\right)}} \\
& I B T C=\sqrt{\frac{D_{i}^{t+1}\left(x^{t}, y^{t}\right)}{D_{i}^{t}\left(x^{t}, y^{t}\right)} \times \frac{D_{i}^{t}\left(x^{t+1}, y^{t}\right)}{D_{i}^{t+1}\left(x^{t+1}, y^{t}\right)}} \\
& \text { MATC }=\frac{D_{i}^{t}\left(x^{t}, y^{t}\right)}{D_{i}^{t+1}\left(x^{t}, y^{t}\right)}
\end{aligned}
$$

...where, MATC reflects the change of the production frontier and belongs to the category of neutral technical progress. OBTC reflects the promotion of technical progress to different proportions of multiple outputs, and when there is a single output, $O B T C=1$. The IBTC reflects changes in the marginal rate of substitution of various inputs by technological progress. When $I B T C>1$, input-biased technological progress has a positive effect on TFP.
It is worth noting that OBTC and IBTC only show the impact on TFP growth. By observing the OBTC and IBTC indices, it is not possible to understand the direction of specific technological progress. Thus, we use the method built by Weber et al. [35] to judge the specific bias of technological progress. This method determines the bias of technological progress by comparing the changes in the ratio of two factors in different periods. So we have compared biased technological progress between energy and labor, between energy and capital, and between marine economic production and environmental output. If the marginal substitution rate of input factors does not change, it is expressed as Hicks' neutral technological progress. Similarly, if the marginal rate of transformation between two output factors is constant, the technological progress on the outputs is neutral. The specific process of judging the bias of technical progress is shown in Table 1. $x_{1}, x_{2}, x_{3}, y_{1}$, and $y_{2}$ in Table 1. represent energy consumption, labour, capital,

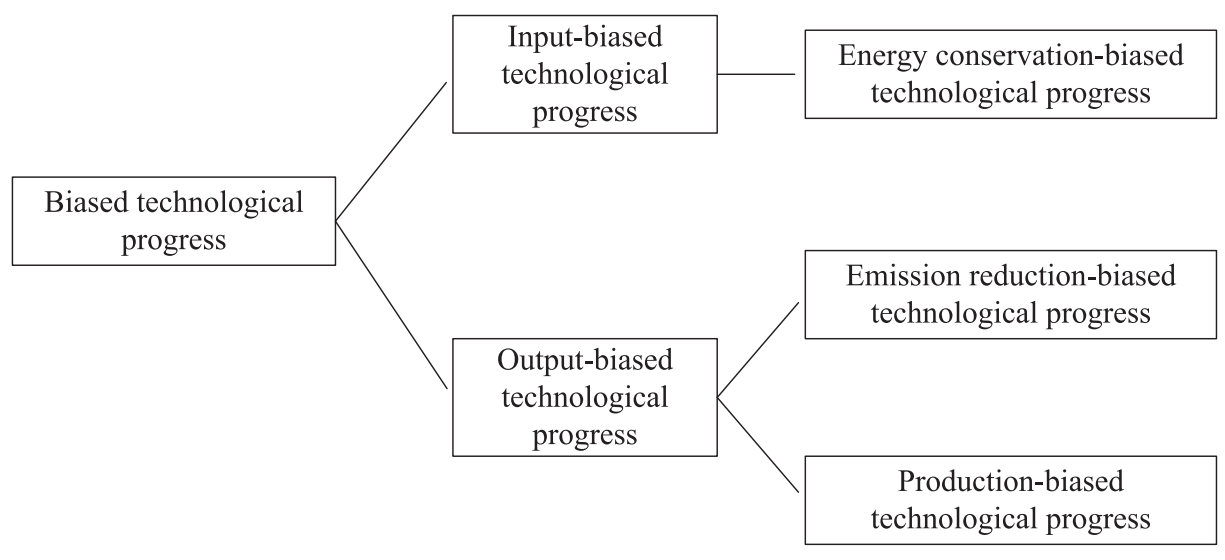

Fig. 1. Types of biased technological progress. 
marine economic production, and environmental output, respectively.

According to Table 1, we propose different types of biased technological progress, as shown in Fig. 1. When the input-biased technological progress is characterized by a bias toward reducing energy consumption, it is defined as the energy conservationbiased technological progress. Similarly, there may be two cases of output-biased technological progress: promoting production or reducing pollution. When the output-biased technological progress shows a reduction in emissions, it is defined as the emission reductionbiased technological progress. Otherwise, it is defined as the production-biased technological progress. This classification of biased technological progress helps to further analyze the dynamics of technological progress in China's marine economic development.

\section{Factors of Biased Technological Progress}

There may be spatial effects in the biased technological progress of the marine economy in 11 coastal areas. Drawing on the research results of the space panel model by Fischer et al. [36], to analyze the influencing factors of biased technological progress, the following space panel model is used:

$$
\begin{aligned}
\text { Biased Technological Progress } & =\rho \sum_{j=1}^{K} W_{i j} \\
\text { Biased Technological Progress } & +\beta X_{i t}+\alpha_{i}+v_{t}+\varepsilon_{i t} \\
\varepsilon_{i t} & =\lambda \sum_{j=1}^{K} W_{i j} \varepsilon_{i t}+\mu_{i t}
\end{aligned}
$$

...where, Biased Technological Progress includes IBTC and OBTC. $X_{i t}$ is the control variable (the influencing factor in this paper is the control variable), which indicates the influencing factors of the biased technological progress in each region. $\alpha_{i}$ and $v_{t}$ are time-invariant and time-varying individual effects, respectively. $\varepsilon_{i t}$ is a random error term. $\rho$ and $\lambda$ are the space after term coefficients and the spatial error term coefficients, respectively, which are used to measure the spatial effect. $\rho$ reflects the influence of changes in a region's variables on its neighboring regions, while $\lambda$ reflects the extent to which changes in variables in adjacent regions affect the region. If $\rho=0$, model (6) is a spatial error model (SEM). When $\lambda=0$, the model (6) is a spatial lag model (SLM). In addition, $W_{i j}$ is a spatial weight matrix, and we use the reciprocal of the distance between the provincial capitals as the spatial weight.

\section{Indicator Selection}

In this study, we select three input and two output indicators to estimate the TFP of marine economy and judge the biased technological progress. The sample data

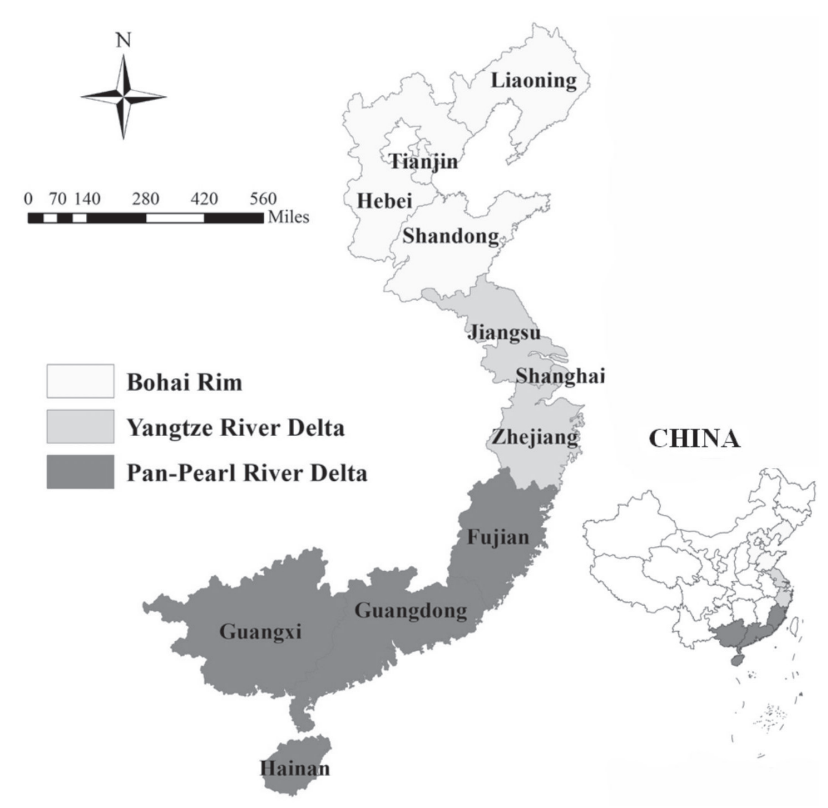

Fig. 2. Three groups of 11 coastal regions.

for this study include data of 11 coastal areas in China from 2002 to 2016. The data are from the China Marine Statistical Yearbook (2003-2017), the China Energy Statistical Yearbook (2003-2017), the China Statistical Yearbook (2003-2017) and the China Environment Statistical Yearbook (2003-2017). These data systems have been widely used to estimate economic efficiency in various fields.

In order to better analyze the regional differences in the biased technological progress of China's marine economy, we divided 11 coastal areas into three groups: Bohai Rim, Yangtze River Delta, and Pan-Pearl River Delta. The Bohai Rim includes Liaoning, Shandong, Tianjin, and Hebei. The Yangtze River Delta consists of Zhejiang, Jiangsu, and Shanghai. Finally, the Pan-Pearl River Delta includes Fujian, Guangxi, Guangdong, and Hainan. Fig. 2. shows the geographical location of the study area. Table 2 . shows the basic characteristics of 11 coastal regions in 2016. Among them, total investment in fixed assets in the whole country shows the size of the investment in fixed assets. The more investment in fixed assets, the greater potential for local development. As can be seen from Table 2, Shanghai has the highest GDP per capita. It is not only one of China's economically developed regions, but also a region with developed marine economies. Guangxi has the largest area but the lowest level of economic development. These basic characteristics are closely related to the development of the local marine economy.

We use the marine capital stock, marine labor and energy consumption as three input indicators of the marine economic production process. This study uses the method proposed by Zhang et al. [37] to estimate the marine capital stock. We assume that the capital stock in 2002 is the original capital stock, and estimate the annual capital stock of 11 coastal areas during 
Table 2. The basic characteristics of 11 coastal regions in 2016.

\begin{tabular}{|c|c|c|c|c|}
\hline Region & Area $\left(10^{4} \mathrm{~km}^{2}\right)$ & $\begin{array}{c}\text { Population } \\
\left(10^{4} \text { people }\right)\end{array}$ & $\begin{array}{c}\text { GDP per capita } \\
\left(10^{3} \text { USD/person }\right)\end{array}$ & $\begin{array}{c}\text { Total Investment in Fixed } \\
\text { Assets in the Whole } \\
\text { Country }\left(10^{9} \text { USD }\right)\end{array}$ \\
\hline Tianjin & 1.13 & 1562 & 16.44 & 482.56 \\
\hline Hebei & 18.77 & 7470 & 6.15 & 453.57 \\
\hline Liaoning & 14.59 & 4378 & 7.26 & 95.60 \\
\hline Shanghai & 0.63 & 2420 & 16.65 & 709.51 \\
\hline Jiangsu & 10.26 & 7999 & 13.84 & 432.52 \\
\hline Zhejiang & 10.20 & 5590 & 12.13 & 331.96 \\
\hline Fujian & 12.13 & 3874 & 10.67 & 761.76 \\
\hline Shandong & 15.38 & 9947 & 9.82 & 475.77 \\
\hline Guangdong & 18.00 & 10999 & 10.57 & 260.53 \\
\hline Guangxi & 23.60 & 4838 & 5.43 & 55.58 \\
\hline Hainan & 3.40 & 917 & 6.34 & 76 \\
\hline
\end{tabular}

the study period according to $k_{t}=(1-\delta) k+I_{t}$. Here $k_{t}$ represents the fixed capital stock, $I_{t}$ is the annual actual capital investment, and $\delta$ is the capital depreciation rate of $10.96 \%$ [13]. Based on this, we have obtained the stock of marine capital. In addition, we use the average annual marine-related employment as an indicator of labor input. Besides capital and labor input, we also add energy consumption of the marine economy to describe the TFP to fully reflect the efficiency of resource utilization. Since there is no specific data on the energy consumption of the marine economy, we estimate it based on the proportion of local GOP in GDP.

This study uses economic output and environmental output as output indicators. From the perspective of economic efficiency, we choose GOP as the expected output, which is a common indicator to measure the marine economic efficiency. Moreover, the environmental output is environmental emission composite index, which includes marine industrial waste water discharge, marine industrial solid waste production and chemical oxygen demand emission in marine industrial waste water. We empower these three indicators through an improved entropy assessment method [15]. Further, we calculate the weighted sum of these three indicators. Finally, in order to obtain a positive environmental output indicator, the environmental comprehensive index is obtained by calculating the reciprocal of the sum value. The specific calculation process is in the Appendix. We use the environmental composite index as an indicator to measure environmental output. The greater the environmental composite index is, the lower the

Table 3. The characteristics of marine economy of 11 coastal regions.

\begin{tabular}{|c|c|c|c|c|c|}
\hline Region & $\begin{array}{c}\text { Marine Capital Stock } \\
\left(10^{9} \text { USD }\right)\end{array}$ & $\begin{array}{l}\text { Marine Labor Force } \\
\qquad\left(10^{4} \text { people }\right)\end{array}$ & $\begin{array}{l}\text { Energy Consumption } \\
\left(10^{5} \text { tons }\right)\end{array}$ & $\begin{array}{c}\text { GOP } \\
\left(10^{9} \mathrm{USD}\right)\end{array}$ & $\begin{array}{l}\text { Environmental } \\
\text { Composite Index }\end{array}$ \\
\hline Tianjin & 74.59 & 160.54 & 180.65 & 29.77 & 65.58 \\
\hline Hebei & 39.97 & 87.53 & 149.04 & 13.11 & 6.59 \\
\hline Liaoning & 82.71 & 295.77 & 252.06 & 25.17 & 8.43 \\
\hline Shanghai & 96.03 & 192.28 & 288.50 & 53.35 & 32.89 \\
\hline Jiangsu & 78.94 & 176.24 & 172.63 & 31.64 & 9.59 \\
\hline Zhejiang & 93.22 & 386.91 & 210.32 & 39.21 & 14.33 \\
\hline Fujian & 103.29 & 391.85 & 218.59 & 42.26 & 15.15 \\
\hline Shandong & 176.86 & 482.24 & 486.26 & 65.92 & 8.04 \\
\hline Guangdong & 143.80 & 761.86 & 415.08 & 86.62 & 10.39 \\
\hline Guangxi & 18.18 & 103.95 & 40.11 & 6.22 & 13.47 \\
\hline Hainan & 16.88 & 121.62 & 35.18 & 5.78 & 161.37 \\
\hline
\end{tabular}


degree of environmental degradation. And the marine economic characteristics of each region are described in Table 3.

The following factors may have different effects on the biased technological progress of marine economy. First of all, environmental regulations (ER) in various regions will have an impact on the local biased technological progress of marine economy. According to Song et al. [32], environmental regulations are usually divided into directives (such as pollution taxes) and incentive regulations (such as the handling of pollution). Therefore, we choose two indicators to measure the impact of environmental regulations. We use the sewage fee income, ER1, and the environmental governance investment, ER2. The large values of ER1 and ER2 indicate that the local environmental supervision is strong. Since the bias of technological progress is not only affected by environmental regulations, the coefficient of ER1 and ER2 cannot be judged in advance. The second is the economic level (EL). EL is defined as the ratio of each region's GOP to the national GOP to measure the level of local economy. Generally, the more developed the economy, the greater the research and development of technology. Therefore, it is initially judged that the biased technological progress and the economic level are positively correlated. The third is foreign direct investment (FDI). It is determined by the ratio of FDI investment to GDP in every coastal area. Foreign direct investment often leads to technology spillovers. At the same time, FDI is also an important source of environmental pollution. Therefore, we cannot judge the positive or negative coefficient of this index. The last one is industrial scale (IS). It is measured by the proportion of the secondary industry to the GDP in every coastal area. Industry is an important source of environmental pollution in coastal areas. Therefore, we regard the industrial scale as the influencing factor of the biased technological progress of the marine economy, and then explore its role in the direction of technical progress. To eliminate the dimensional problems of different variables and to avoid heteroscedastic problem, we use the logarithm of the variables involved in the model.

The descriptive statistics for all data are shown in Table 4.

\section{Results and Discussion}

\section{TFP Growth and Biased Technological Progress}

Fig. 3 reveals the trend of TFP growth from 2002 to 2016 in China's coastal areas. As shown in Fig. 3, the MIs between 2002 and 2016 are basically greater than 1 , indicating that the TFP of marine economy increases generally, although its growth rate fluctuates. This is consistent with the research of Ding et al [15]. The MI was in a declining stage in 2006-2008, probably because the Eleventh Five-Year Plan made the government begin to focus on the healthy development of China's marine economy, rather than blindly pursuing economic growth. At the same time, the global financial crisis in 2008 also caused a certain impact on China's marine economy. In addition, there was a brief decline in total factor productivity in 2010-2011. The trends of TC and MI are similar, as the increase of marine economic TFP is mainly owing to the positive effect of technological progress rather than the improvement of technical efficiency. In addition, the MI and TC indices showed dramatic fluctuations between 2006 and 2011. This may be because China's environmental regulatory policy has achieved certain results, and technological innovation has been further developed. In short, as shown in Fig. 3, the growth of China's marine economic TFP increases over the sample period. And TCs have an important role in promoting the growth of total factor productivity. Even in some periods, technological progress can also reduce the negative impact of inefficiency.

Table 4. Descriptive statistics of inputs, outputs and influencing factors.

\begin{tabular}{|c|c|c|c|c|c|c|}
\hline & Variable & Description of Variable & Mean & $\operatorname{Max}$ & Min & SD \\
\hline \multirow{3}{*}{ Inputs } & Capital & Marine Capital Stock ( $10^{9}$ USD) & 84.04 & 476.78 & 1.37 & 80.75 \\
\hline & Labor & Marine Labor Force $\left(10^{4}\right.$ people $)$ & 287.35 & 868.50 & 69.37 & 200.13 \\
\hline & Energy & Energy Consumption ( $10^{5}$ tons) & 222.58 & 755.99 & 7.21 & 163.57 \\
\hline \multirow{2}{*}{ Outputs } & Expected Output & GOP (109 USD) & 36.28 & 169.74 & 0.81 & 32.90 \\
\hline & Environmental Output & Environmental Composite Index & 31.44 & 229.60 & 3.21 & 47.12 \\
\hline \multirow{5}{*}{$\begin{array}{l}\text { Influencing } \\
\text { factors }\end{array}$} & \multirow{2}{*}{$\begin{array}{l}\text { Environmental } \\
\text { Regulations (ER) }\end{array}$} & Sewage Fee Income ( $10^{6}$ USD) & 104.23 & 358.72 & 1.74 & 82.28 \\
\hline & & Environmental Governance Investment ( $10^{6}$ USD) & 362.78 & 2022.86 & 1.43 & 331.82 \\
\hline & Economic Level (EL) & Ratio of Each Region's GOP to National GOP (\%) & 9.09 & 25.59 & 0.66 & 6.26 \\
\hline & $\begin{array}{l}\text { Foreign Direct Investment } \\
(\text { FDI })\end{array}$ & Ratio of FDI to GDP (\%) & 76.63 & 584.94 & 11.63 & 70.95 \\
\hline & Industrial Scale (IS) & Ratio of Secondary Industry to GDP (\%) & 47.31 & 60.13 & 20.75 & 8.51 \\
\hline
\end{tabular}




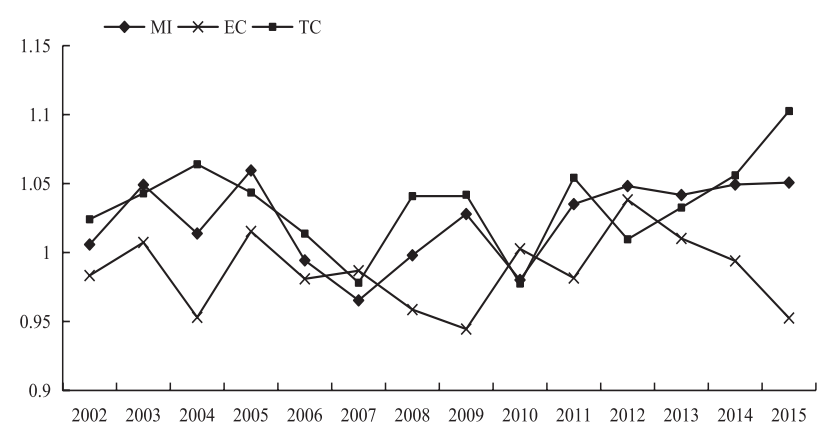

Fig. 3. MI, EC and TC indices during the period of 2002-2016.

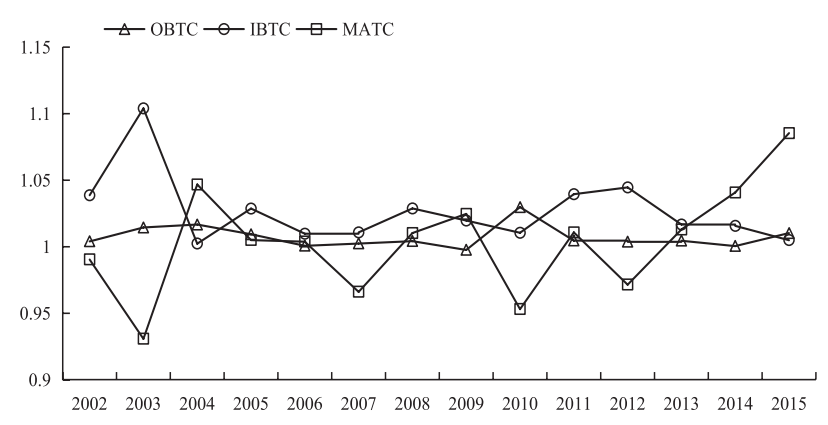

Fig. 4. OBTC, IBTC and MATC indices during the period of 2002-2016

By further decomposing TCs, we can better analyze the biased technological progress of the marine economy. Fig. 4 shows the decomposition of TCs, including IBTC, OBTC, and MATC. As shown in Fig.4, IBTC and OBTC show resemble trends. In turn, the MATC fluctuates relatively sharply. This means that scale changes are still important to marine economy. These results are showing no difference with before studies that early marine economy is seriously dependent on the expansion of efficiency. Meanwhile, the constant changes in the government's environmental policies have led to continued volatility in the IBTC and OBTC indices over the study period.

Fig 5. provide a discussion about the spatial distribution of the Malmquist productivity index. This study only covers 11 coastal areas, so according to the MI index, we divide them into three grades to analyze the spatial structure of marine economy. First, MIs in 2002 are identified as 1, and then we select some special time points during the study period to determine the spatial distribution. With the continuous development of China's marine economy, it has become more and more similar to the development of national economy. In particular, a series of policies formulated by the Chinese government have pointed out the direction for the development of marine economy. Therefore, we select the starting times of the $11^{\text {th }}$ Five-Year Plan and the $12^{\text {th }}$ Five-Year Plan as dividing points, and divide the research period into 2002-2006, 2006-2011 and 2011-2016, so as to deeply analyze the changes of TFP in various coastal areas.
As shown in Fig 5., during the period of 2002-2006, Hebei, Tianjin, Shanghai, and Guangdong were in highvalue areas. Shandong, and Zhejiang were in mediumvalue areas, while Liaoning, Jiangsu, Fujian, Guangxi, and Hainan were in low-value areas. The early marine economy was only a small part of the national economy in China. The development level of marine economic was low and the technology was not developed. Thus, the low-pollution traditional industries such as the marine salt industry and fisheries were the main marine industries in the coastal areas during the period of 2002-2006. Early marine economic production also has less pollution and damage to the environment. The rapid development of the marine economy in Hebei, Tianjin, Shanghai, and Guangdong positively affects by the inland economy. However, the development of marine economy in Hainan is relatively special, mainly because tourism is its pillar industry. Although tourism has less pollution, as main industry it has led to a lack of incentives for productivity growth in Hainan. During the period of 2006-2011, the spatial distribution of the MI has changed a lot. Fujian has become a highvalue area, probably owing to the rapid development of local international trade. The marine economy in Hebei and Shandong has shown a slow development, which means that the contradiction between the rapid expansion of the marine economy and environmental pollution has become increasingly severe. In 2011-2016, the government proposed a sustainable development path for the marine economy. Marine resources and environmental protection have become the focus of work in various coastal areas. Thus, Shandong, Jiangsu, and Zhejiang became high-value areas. At the same time, China's new normal has led to a slowdown in economic growth. Hebei, Tianjin, and Guangdong must actively respond to the pressure of marine economic growth. Because their marine economic efficiency is reduced by the cost of resources and environmental governance. Through the above analysis, we can find that most of China's 11 coastal areas belong to high-value areas and medium-value areas, and the spatial distribution of marine economic productivity is relatively stable.

At the same time, as shown in Fig 6., the growth of the marine economy in various coastal areas mainly depends on technological progress. Due to the special nature of its industrial structure, Hainan's marine economy is still driven by efficiency. This is why it is a low-value area. These findings are not completely consistent with the research by Ding et al. [4], which may be due to the different study periods and choice of indicators. But the overall growth trend and regional imbalances in China's marine economy do exist.

As can be seen from the foregoing, if the inputbiased technological progress index is not less than 1, it means that technological progress will at least not reduce productivity. According to Table 5, except for Hebei, the IBTCs of other coastal areas are greater than 1, indicating that the input-biased technological progress has promoted the improvement of marine 

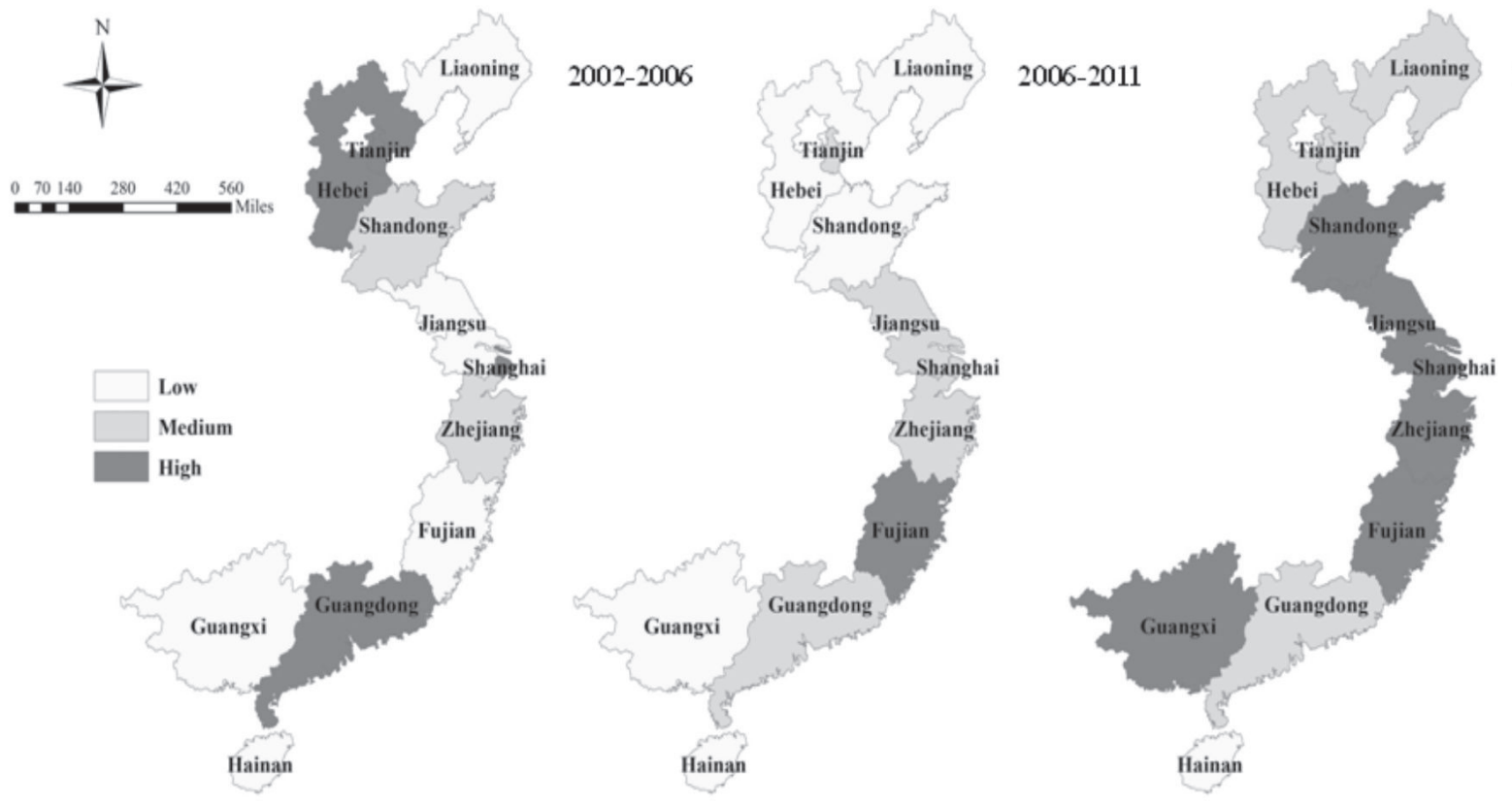

2011-2016

Fig. 5. MI in China's coastal areas.

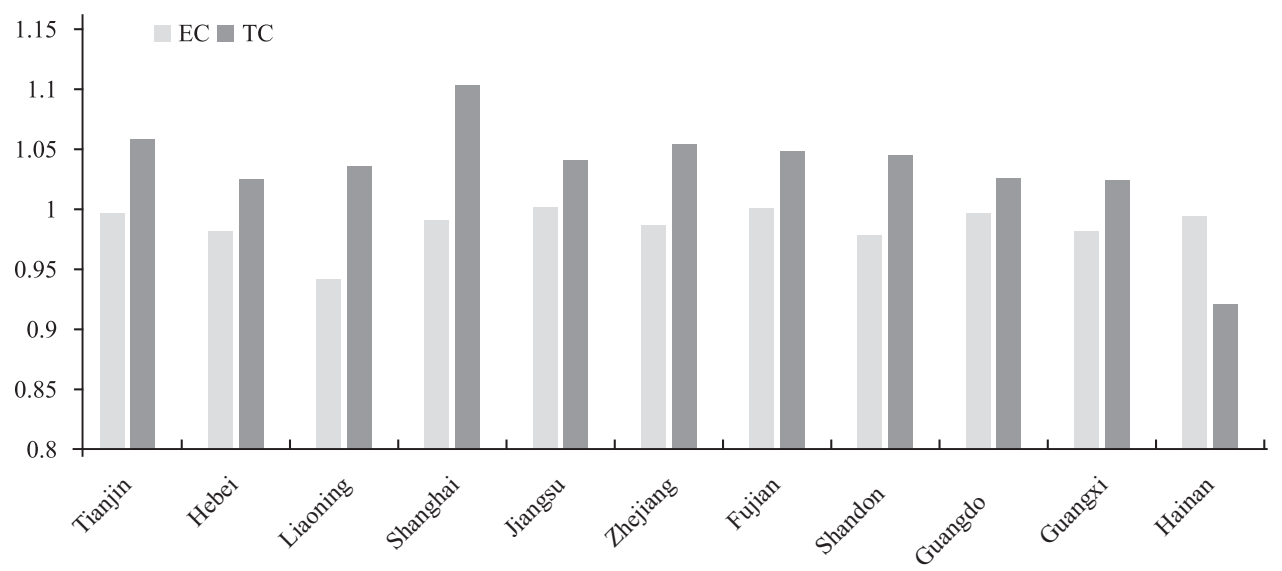

Fig. 6. EC and TC indices in China's coastal areas.

economic productivity in most coastal areas. As a developed area of marine economy, Shanghai's inputbiased technological progress has positively affected the growth of TFP with a growth rate of $9 \%$. In addition, from the perspective of output factors, due to the existence of environmental output's special attributes, we can not make the output-biased technological progress index greater than 1 as a one-sided pursuit of technological progress. If the OBTC index is greater than 1 , it indicates that technological progress contributes to the different proportions of multiple outputs, including the separate effects on economic and environmental outputs. Whether the output-biased technological progress exerts a positive or negative impact on the marine economy can be determined after analyzing the output ratios in different periods and obtaining the specific bias of the technological progress.
But overall, output-biased technological advances have contributed to marine economic productivity in 11 coastal areas between 2002 and 2016. In addition, the MATC index in most regions is greater than 1, except for Shanghai, Guangdong, and Hainan. This indicates that technological scale effects still exist in most coastal areas. Therefore, attention must be paid to all coastal areas, and differences of marine economic development in various regions cannot be ignored.

\section{Specific Biased Analysis of Technological Progress}

The IBTC and OBTC indices cannot directly show the specific bias of technological progress. Only by combining the analysis of relevant input and output factors can we determine the factors that are 
Table 5. Comparison of regional biased technological change.

\begin{tabular}{|c|c|c|c|}
\hline Region & IBTC & OBTC & MATC \\
\hline Tianjin & 1.015 & 1.005 & 1.0363 \\
\hline Hebei & 0.999 & 1.001 & 1.0249 \\
\hline Liaoning & 1.002 & 1.000 & 1.0335 \\
\hline Shanghai & 1.093 & 1.013 & 0.9962 \\
\hline Jiangsu & 1.009 & 1.000 & 1.0318 \\
\hline Zhejiang & 1.012 & 1.000 & 1.0437 \\
\hline Fujian & 1.021 & 1.001 & 1.0290 \\
\hline Shandong & 1.016 & 1.000 & 1.0288 \\
\hline Guangdong & 1.033 & 1.000 & 0.9932 \\
\hline Guangxi & 1.006 & 1.002 & 1.0165 \\
\hline Hainan & 1.089 & 1.059 & 0.8075 \\
\hline Mean & 1.027 & 1.007 & 1.0363 \\
\hline
\end{tabular}

saved or used in the production. As highlighted in Section 2, A specific biased technological progress can be determined by judging the factor ratios at different times. Table 6 summarizes the specific types of biased technological progress.

We analyzed the two indicators in the input (Energy/Labor and Energy/Capital) and got the following conclusions. As a whole, IBTC reveals that technological progress of China's marine economy is biased towards using energy and saving labor during the study period. This is largely due to the relatively abundant resources of China, so the scale of use of rich elements is expanded. Second, the input-biased technological progress used energy, conserved capital between 2002 and 2006, while using capital and saving energy during the period of 2006-2016. These changes indicate that with the rapid growth of economy, capital elements are continuously enriched, and the awareness of building a resource-saving society is gradually strengthened. The proportion of energy conservationbiased technological progress in Fig. 7 is relative to labor and capital, so we can compare the different types of the biased technological progress in the three groups

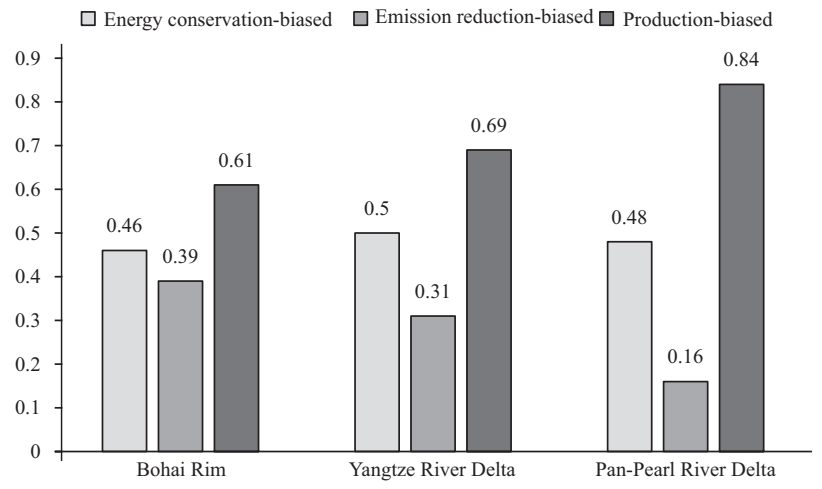

Fig. 7. Proportion of DMUs in different biased technological progress.

of regions. Fig. 7 reveals that the technological progress in the Yangtze River Delta is more in favor of saving energy than that in other regions. but the differences are not obvious.

We compared the ratios of two outputs (GOP/ Environmental Composite Index) in different periods and analyzed them with the OBTC index to judge the type of output-biased technological progress. We have gained some important conclusions. Technical progress was more biased towards promoting production in the period of 2002-2016. Despite this, the proportion of emission reduction-biased technological advances has gradually increased. This is closely related to the introduction of relevant policies and the continuous increase of investment in environmental governance by the state. Fig. 7 shows that production-biased technological progress accounts for the largest proportion. The technological progress in the Pan-Pearl River Delta region is more inclined to promote the growth of production, while the Bohai Rim pays most attention to environmental protection compared to the Yangtze River Delta and the Pan-Pearl River Delta. The industries in Liaoning and Shandong are relatively developed, so the government pays more attention to environmental pollution. Strict environmental regulations have prompted these regions to show emission reduction-biased technological progress. However, coastal tourism in the Pan-Pearl River Delta

Table 6. Proportion of DMUs in specific bias of technological change in different periods. (\%).

\begin{tabular}{|c|c|c|c|c|}
\hline Technological change & Specific bias & $2002-2006$ & $2006-2011$ & $2011-2016$ \\
\hline \multirow{3}{*}{ IBTC } & Energy conservation-biased & 30 & 31 & 31 \\
\cline { 2 - 5 } & Labor conservation-biased & 70 & 69 & 69 \\
\cline { 2 - 5 } & Energy conservation-biased & 41 & 76 & 73 \\
\cline { 2 - 5 } & Capital conservation-biased & 59 & 24 & 27 \\
\hline \multirow{3}{*}{ OBTC } & Emission reduction-biased & 16 & 27 & 40 \\
\cline { 2 - 5 } & Production-biased & 84 & 2 & 60 \\
\cline { 2 - 5 } & Technical neutral & 0 & & 0 \\
\hline
\end{tabular}


Table 7. Spatial correlation test results.

\begin{tabular}{|c|c|c|c|}
\hline Variable & Moran's I & Z & p-value \\
\hline IBTC & -0.036 & -3.639 & 0.000 \\
\hline OBTC & -0.019 & -1.804 & 0.036 \\
\hline
\end{tabular}

is relatively developed and the environmental quality is relatively high. Therefore, increasing the economic output of the marine economy has become the development focus of the Pan-Pearl River Delta.

\section{Analysis of Influencing Factors for Biased Technological Progress}

Before applying the spatial panel model, we first examined the spatial correlation of the explanatory variables. Moran's I is employed to analyze the spatial effects among 11 coastal regions based on their biased technological progress. The results are listed in Table 7. The IBTC's Moran's I value is -0.036 and $\mathrm{p}$-value is 0 . At the same time, the Moran's I value of OBTC is -0.019 and p-value is 0.036 . It can be seen that the biased technological progress in each region does have a spatial correlation and a significant negative spillover effect, so a spatial panel model can be established for research.

The Hausman test determines that the spatial panel model of random effects is more suitable for this study. Among the random effects, the commonly used spatial models mainly include spatial lag model (SLM) and spatial error model (SEM). The results of the SLM and SEM tests are shown in Table 8.

According to Table 8, the results of SLM and SEM are basically similar, indicating that the regression results have certain robustness. The sewage fee income has a negative correlation with IBTC, which indicates that the IBTC index declines when sewage fee income is too high in a particular province. The governance investment and the input-biased technological progress also show a negative correlation, but it does not pass the significant test. This may be because pollution control is mainly to use existing technologies and less to develop new technologies. At the same time, these results also reveal that directive environmental regulations tend to affect input-biased technological progress more easily than incentive environmental regulations. Economic level influences the IBTC index. Governments in regions with a higher economic level tend to encourage technical innovations that promote the rational use of inputs. A high-quality economic environment will promote technological progress. The result for FDI in terms of input-biased technological progress is negative. This result reflects that the inflow of foreign capital is not conductive to input-biased technological progress. This is mainly because foreign investors are more likely to use cheap labor in China, and they do not pay attention to technological progress. At the same time, the richness of China's resources is higher than that of foreign countries. Therefore, foreign direct investment will not bring about the improvement of technology. The correlation among industrial scale and IBTC indices is negative, indicating that industrial scale can not promote input-biased technological progress. The larger the industry, the higher the income, the lower the sensitivity to prices, resulting in poor innovation awareness.

The regression results of each variable on IBTC and OBTC are mainly similar. Specifically, the economic level increases the output-biased technological progress, whereas sewage fee income, governance investment, foreign direct investment and industrial scale, decrease it. Table 8 reflects that all influencing factors, except for the sewage fee income and economic level have significant effects on OBTC. In addition, governance

Table 8. Results of the spatial panel model.

\begin{tabular}{|c|c|c|c|c|}
\hline \multirow{2}{*}{} & \multicolumn{2}{|c|}{ SLM } & \multicolumn{2}{c|}{ SEM } \\
\cline { 2 - 5 } & IBTC & OBTC & IBTC & -0.0015 \\
\hline $\operatorname{lnER} 1$ & $-0.0188^{* * *}$ & -0.0017 & $-0.0172^{* * *}$ & $-0.0092^{* * *}$ \\
\hline $\operatorname{lnER} 2$ & -0.0039 & $-0.0091^{* * *}$ & -0.0016 & $0.0048^{*}$ \\
\hline $\operatorname{lnEL}$ & $0.0213^{* * *}$ & $0.0048^{*}$ & $0.0195^{* * *}$ & -0.0040 \\
\hline $\operatorname{lnFDI}$ & -0.0027 & -0.0044 & -0.0001 & $-0.0326^{* *}$ \\
\hline $\ln \mathrm{SS}$ & $-0.0552^{* *}$ & $-0.0341^{* * *}$ & $-0.0584^{*}$ & $0.1482^{* * *}$ \\
\hline Constant & $0.2247^{* *}$ & $0.1529 * * *$ & $0.2425^{* *}$ & - \\
\hline$\rho$ & $40.5100^{* * *}$ & 7.6401 & - & 7.7345 \\
\hline$\lambda$ & - & - & $43.6342^{* * *}$ & 0.3721 \\
\hline $\mathrm{R}^{2}$ & 0.3715 & 0.3722 & 0.3489 & 381.4211 \\
\hline
\end{tabular}

Notes: $* * *, * *$, and $*$ indicate statistical significance at the $1 \%, 5 \%$, and $10 \%$ levels, respectively. 
investment has a greater impact on OBTC than on IBTC. Output-biased technological progress is more susceptible to governance investments in marine environment than to sewage charges. At the same time, the government's increased investment in environmental pollution control will inhibit output-biased technological advances. Contrary to the findings of Song et al. [32], we find that incentive environmental regulations have a stronger effect on output-biased technological progress of marine economy than directive environmental regulations do. This shows that the government should adhere to the principle of source governance when formulating environmental policies in China. The effects of the sewage fee income and the foreign direct investment on the output-biased technological progress are negative, indicating that these indicators cannot directly accelerate the green development of the marine economy.

\section{Conclusions}

The paper attempts to estimate the input-biased and output-biased technological progress of China's marine economy from 2002 to 2016. Energy and marine environment are two factors that constrain the highquality development of marine economic. To study the development of marine economy, it is necessary to consider the problems of energy and pollution. Especially, innovation is the main driving force to promote the high-development of marine economy. Therefore, this paper uses a DEA model to measure the biased technological progress of 11 coastal areas in China. We further identified specific biased factors for technological progress and then analyzed its influencing factors.

We find that the TFP of marine economy is gradually increasing, and this growth is mainly driven by technical progress. The biased technological progress has promoted the sustainable development of China's marine economy. In addition, the inputbiased technological progress in most coastal areas can promote the productivity of marine economy, but it is more likely to overuse energy. The OBTC index shows that many coastal regions prefer to increase economic output and aggravate pollution. However, the emission reduction-technological progress has received increasing attention. In addition, the three regions focus on different types of biased technological progress. For instance, the technological progress in the Yangtze River Delta is more conducive to saving energy than that in other regions Technological progress in the PanPearl River Delta is more biased towards promoting production, while the Bohai Rim pays most attention to environmental protection compared to the Yangtze River Delta and the Pan-Pearl River Delta. In general, the technological progress of marine economic is gradually becoming conducive to the conservation of energy and the reduction of pollution. Factors such as environmental regulation and industrial scale in various regions have a significant negative impact on biased technological progress, while the economic level has a significant role in promoting biased technological progress. Among them, the directive's regulations have a greater impact on the development of input-biased technology, while the incentive regulations have a greater impact on the development of output-biased technological progress.

The conclusions of this paper can bring certain policy implications. With its high-quality development, the marine economy should rely on green technology to achieve healthy growth. In order to implement the strategy of maritime power and promote the development of the marine economy, the State Oceanic Administration of China has compiled the "Thirteenth Five-Year Plan" for the development of the nation's marine economy. It is proposed to promote the optimization and upgrading of marine industry, promote the innovative development of the marine economy and strengthen the construction of marine ecological civilization. Thus, Green technology innovations that promote energy conservation and environmental protection should be encouraged. In addition, since environmental regulation will have an important impact on the development of biased technology, policy makers should fully consider the different roles of directives and incentive regulations when formulating policies. Only by adhering to the principle of "governance from the source" can we truly promote environmentally biased technological progress and reduce pollution emissions, thereby accelerating the green development of marine economy. Especially, As China's economy has moderated to a new normal and economic growth has slowed down, it is more important to promote the coordinated development of the economy and the environment. Also, China must be devoted to improving energy conservation-biased and emission reductionbiased technological progress and simultaneously realize both technological progress and environmental protection. For instance, the green technology in the Pan-Pearl River Delta region is relatively mature, and its green technology should be encouraged to gradually spread to other regions.

The EU's Limassol Declaration explicitly proposed a blue economy for wise, sustainable and inclusive growth. In 2019, Chinese President Xi Jinping clearly put forward the concept of building a "Marine Destiny Community". It is in the same vein as the "Community of Human Destiny" and aims to build an efficient and fair global ocean governance system. Hence, promoting the development of biased technology towards energy conservation and emission reduction can promote the steady implementation of Europe's blue economy plan. And the green development path of China's marine economy can provide reference for the development of European blue economy. 


\section{Appendix}

This paper attempts to use an entropy method to determine the index weight by its degree of variation. The environmental comprehensive index constructed by the entropy method is used as the environmental output. The detailed process is as follows:

First, all indicators are dimensionless.

$$
X_{i j}^{\prime}=\frac{X_{j}}{\sum_{i=1}^{m} X_{j}}
$$

...where, $X_{i j}=\left(x_{i j}\right)_{m \times n}$ is the data matrix of the original indicator. $x_{i j}$ is the value of the $j$ th indicator of region $\mathrm{i}$. Then, $X_{i j}^{\prime}=\left(x_{i j}^{\prime}\right)_{m \times n}$.

$$
\begin{aligned}
& e_{j}=\frac{1}{\mathrm{~h} m} \sum_{i=1}^{m} X_{j}^{\prime} \mathrm{h} x_{j}^{\prime}, e_{j} \geq 0 \\
& e_{j}^{\prime}=1-e_{j}
\end{aligned}
$$

...where, $e_{i}, e^{\prime}$ is the entropy and difference coefficient of index $j$. The larger $e_{i j}^{\prime}$, the more important the indicator $j$ is in the comprehensive evaluation. Then we calculate the weight of the indicator $j$ by the following formula.

$$
w_{j}=\frac{e_{j}^{\prime}}{\sum_{j=1}^{n} e_{j}^{\prime}}
$$

Finally, we can calculate the environmental comprehensive index as follows:

$$
\text { Environmental Comprehensive Index }=\left(\sum_{j=1}^{n} X_{j}^{\prime} W_{j}\right)^{-1}
$$

The greater the environmental comprehensive index, the smaller the pollution emissions from marine economic production.

\section{Acknowledgements}

This research is supported by the National Natural Science Foundation of China (Nos. 71371111; 71973132).

\section{Conflict of Interest}

The authors declare no conflict of interest.

\section{References}

1. KEEN M.R., SCHWARZ A.M., WINI-SIMEON L. Towards defining the Blue Economy: Practical lessons from pacific ocean governance. Marine Policy, 88 (2), 333, 2018.

2. European Commission. Blue Economy Report., 2018.

3. YU C., SHI L., WANG Y.T., CHANG Y., CHENG B.D. The eco-efficiency of pulp and paper industry in China: an assessment based on slacks-based measure and MalmquistLuenberger index. Journal of Cleaner Production, 127, 511, 2016.

4. DING L.L., ZHENG H.H., ZHAO X. Efficiency of the Chinese ocean economy within a governance framework using an improved Malmquist-Luenberger index. Journal of Coastal Research, 34 (2), 272, 2018.

5. DOUVERE F. The importance of marine spatial planning in advancing ecosystem-based sea use management. Marine Policy, 32 (5), 762, 2008.

6. KWAK S.J., YOO S.H., CHANG J.I. The role of the maritime industry in the Korean national economy: an input-output analysis. Marine Policy, 29 (6), 371, 2005.

7. KARYN M. Using secondary data to examine economic trends in a subset of sectors in the English marine economy: 2003-2011. Marine Policy, 50 (4), 135, 2014.

8. ZHAO X., XUE Y.M., KANG W.L., DING L.L., ZHU L. Measuring efficiency of ocean economy in China based on a novel Luenberger approach. Romanian Journal of Economic Forecasting, 21 (2), 5, 2018.

9. DING L.L., LEI L., WANG L., ZHANG L,F., CALIN A.C. A novel cooperative game network DEA model for marine circular economy performance evaluation of China. Journal of Cleaner Production, 253 (1), 1, 2020.

10. XU S., SI D. Study on marine industry carbon emissions performance in blue economic zone. Areal Research and Development, 33 (3), 122, 2014.

11. KARYN M., CATHAL O. The Irish marine economy and regional development. Marine Policy, 36 (8), 358, 2012.

12. SARKER S., BHUYAN .A.H., RAHMAN M.M., ISLAM A., HOSSAIN S., BASAK S.C., ISLAM M.M. From science to action: Exploring the potentials of Blue Economy for enhancing economic sustainability in Bangladesh. Ocean \& Coastal Management, 157 (5), 180, 2018.

13. DING L.L., ZHU L., HE G.S. Measurement and influencing factors of green total factor productivity of marine economy in China. Forum on Science and Technology in China, 2 (2), 72, 2015.

14. COLGAN C.S. The ocean economy of the United States: Measurement, distribution, \& trends. Ocean \& Coastal Management, 71 (9), 334, 2013.

15. DING L.L., ZHENG H.H., KANG W.L. Measuring the green efficiency of ocean economy in China: an improved Three-Stage DEA model. Romanian Journal of Economic Forecasting, 20 (1), 5, 2017.

16. ZAPELLONI G., GARCIA RELLAN A., BELLO BUGALLO P.M. Sustainable production of marine equipment in a circular economy: deepening in material and energy flows, best available techniques and toxicological impacts. Science of The Total Environment, 687 (10), 991, 2019.

17. HICKS J.R. The theory of wages. 2nd ed,; Macmillan: London, UK, 1932.

18. LEE J.W., WIE D. Technological change, skill demand, and wage inequality: evidence from Indonesia. World Development, 67, 238, 2015.

19. JUNGA S., LEEB J.D., HWANGC W.S., YEOB Y. Growth versus equity: A CGE analysis for effects of factor-biased technical progress on economic growth and employment. Economic Modelling, 60, 424, 2017. 
20. ACEMOGLU D. Why do new technologies complement skills? directed technical change and wage inequality. Quarterly Journal of Economics, 113 (4), 1055, 1998.

21. ACEMOGLU D. Equilibrium bias of technology. Econometrica, 75 (5), 1371, 2007.

22. ACEMOGLU D. Localised and biased technologies: Atkinson and Stiglitz's new view, induced innovations, and directed technological change. Economic Journal, 125 (583), 443, 2015.

23. DASGUPTA S., ROY J. Understanding technological progress and input price as drivers of energy demand in manufacturing industries in India. Energy Policy, 83, 1, 2015.

24. KANG Z.Y., LI K., QU J.Y. The path of technological progress for China's low-carbon development: Evidence from three urban agglomerations. Journal of Cleaner Production, 178, 644, 2018.

25. FANA M.Q., ZHENG H.T. The impact of factor price changes and technological progress on the energy intensity of China's industries: Kalman filter-based econometric method. Structural Change and Economic Dynamics, 49, 340, 2019.

26. WEI Z.X., HAN B.T., HAN L., SHI Y.Y. Factor substitution, diversified sources on biased technological progress and decomposition of energy intensity in China's high-tech industry. Journal of Cleaner Production, 231, 87, 2019.

27. SONG M.L., WANG S.H. Can employment structure promote environment-biased technical progress? Technological Forecasting \& Social Change, 112, 285, 2016.

28. SONG M.L., WANG S.H. Market competition, green technology progress and comparative advantages in China. Management Decision, 56 (1), 188, 2018.
29. 2 SONG M.L., GAO S.P., WANG S.H. The impact of knowledge trade on sustainable development and environment-biased technical progress. Technological Forecasting and Social Change, 144, 512, 2019.

30. SONG M.L., WANG S.H. Measuring environment-biased technological progress considering energy saving and emission reduction. Process Safety and Environmental Protection, 116, 745, 2018.

31. LI J., SEE K.F., JIN C. Water resources and water pollution emissions in China's industrial sector: A greenbiased technological progress analysis. Journal of Cleaner Production, 229, 1412, 2019.

32. SONG M.L., WANG S.H., WU K.Y. Environment-biased technological progress and industrial land-use efficiency in China's new normal. Annals of Operations Research, 268 (2), 425, 2018.

33. JI Y.B., WANG Y.P. Some comments on Antonelli and Quatraro's paper of measuring effect of biased technology on TFP. Journal of Technology Transfer, 39 (2), 276, 2014.

34. FARE R., GRIFELL-TATJE E., GROSSEKOPE S. Biased technical change and the Malmquist productivity index. Skcandinavian Journal of Economics, 99 (1), 119, 1997.

35. WEBER W.L., DOMAZLICKY B.R. Total factor productivity growth in manufacturing: a regional approach using linear programming. Regional Science and Urban Economics, 29 (1), 105, 1999.

36. FISCHER M.M., SCHERNGELL T., REISMANN M. Knowledge spillovers and total factor productivity: evidence using a spatial panel data model. Geographical Analysis, 41 (2), 204, 2004.

37. ZHANG J., WU G., ZHANG J.P. The estimation of China's provincial capital stock over 1952-2000. Economic Research in China, 10 (10), 35, 2004. 